\title{
Sinkhole treatment to improve water quality and control erosion in southeastern Minnesota
}

\author{
ART KALMES Barr Engineering Company, Minneapolis, Minn., USA \\ ERIC MOHRING Minnesota Board of Water and Soil Resources, St. Paul, Minn., USA
}

\begin{abstract}
Sinkholes in the karst region of southeastern Minnesota present a concern because of potential water quality degradation, erosion, and unsafe conditions. The State of Minnesota recently launched a program to provide costshare and technical assistance to several counties for developing measures to reduce these concerns. Sinkhole treatments such as surface water controls, sinkhole filling techniques, and other specialized treatments were evaluated for implementation under this program.

A review of available literature and our experience revealed that, although there were many methods of sinkhole treatment available, a design methodology or framework for selection of the proper treatment method was not available. A design methodology was developed to assist county Soil and Water Conservation District technicians in screening potential sinkhole treatment sites and evaluating possible sinkhole treatments. The methodology for sinkhole treatments was based on the treatment objective, physical conditions of the sinkhole or the sinkhole site, and economics.

Several projects were put in place to reduce pollution of groundwater from agricultural and residential sources and to prevent erosion of soil into sinkholes. A particularly interesting project involved diverting surface water away from a streamsink that had been shown by dye tracing to be connected to a spring supplying an important state fish hatchery. The sink was suspected of being a major contributor to elevated sediment, nitrate, and pesticide concentrations in the springs, particularly following runoff events. Preliminary results indicate the diversion was successful in improving water quality to the hatchery springs.
\end{abstract}

\section{INTRODUCTION}

Sinkholes and other karst features occur in a region of southeastern Minnesota, northeastern Iowa, and southwestern Wisconsin known locally as the "driftless area." This region was missed by the last (Wisconsinan) glaciation, and is characterized by carbonate bedrock at or near the land surface.

Sinkholes can accelerate groundwater contamination by allowing surface runoff to enter directly into the groundwater system. Sinkholes are also of concern because of increased erosion potential and potential damage to man-made structures as a result of collapse. A variety of activities on the land's surface can harm groundwater through sinkholes, including runoff from cropland and feedlots, stormwater runoff, waste disposal, drainage tile outlets, and any other contaminant-generating activity in a sinkhole's contributing drainage area.

The State of Minnesota recently established a program to provide cost-share and technical assistance to landowners, via county Soil and Water Conservation Districts (SWCDs), for measures to reduce these concerns. Under this program, sinkhole treatments such as surface water controls, sinkhole filling techniques, and other treatments have been put in place to reduce pollution of groundwater from agricultural and residential sources and to prevent erosion of soil into sinkholes. 
Table 1: SINKHOLE TREATMENT PRACTICES

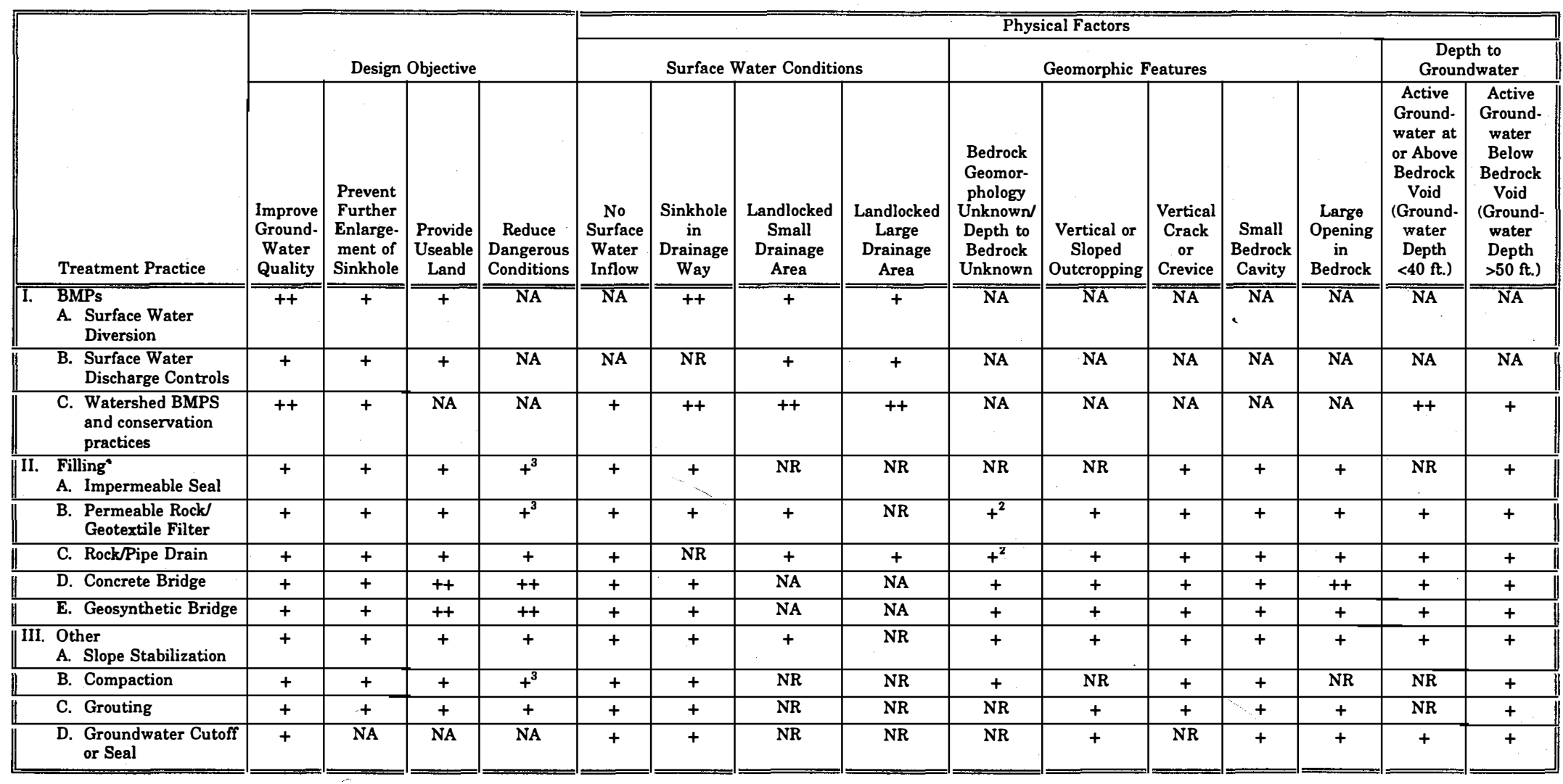

++Desirable solution (considering generally expected cost of implementation, impacts on environment, likelihood of long-term integrity, and constructibility).

NR - Not recommended in most cases without further study.

NA - Not applicable or not a factor in selection of this treatment practice.

${ }^{1}$ Depends on constituents that could degrade groundwater quality, watershed factors, and

${ }^{2}$ Will be a blanket filter. Further subsidence is possible.

'Filling other than concrete bridge is not considered to be a permanent treatment practice. 


\section{PROGRAM BACKGROUND}

In 1991, the Minnesota State Legislature, through the Minnesota Board of Water and Soil Resources (BWSR), provided funds that augmented the existing state cost-share program to include conservation practices specific to sinkholes. The program provided funding to seven Soil and Water Conservation Districts (SWCDs) in southeastern Minnesota. The funding was provided to SWCDs to share in the cost of conservation and water quality practices in sinkholes adjacent to them and in their catchment areas.

The program also provided technical and engineering support to participating SWCDs. A contract was developed with Barr Engineering Company to provide engineering services to SWCDs for projects beyond their capabilities and outside standard practices. A guidance document was prepared to assist SWCDs in evaluating possible treatments.

The program emphasized sites where innovative practices could be used and where there was a high potential for education and demonstration. The sinkhole treatments implemented under this program are mainly smaller projects in rural areas designed to control water quality and erosion. Projects funded under this program include two diversion projects with construction costs between $\$ 50,000$ and $\$ 100,000$ and 25 smaller-scale projects, most with construction costs less than $\$ 5,000$. One of the diversion projects is discussed in more detail in this paper.

\section{BASIS FOR SINKHOLE TREATMENTS}

The program emphasized a multidisciplinary approach to sinkhole treatments. Before treatments were designed, a multiagency task force developed criteria for selecting and treating sinkhole sites. The criteria considered: 1) the characteristics of the sinkhole itself, including morphology, hydrologic setting, materials in the sinkhole, and potential for contaminant "run-in"; 2) the characteristics of the sinkhole's drainage area, including soils, land use, and potential contaminant sources; and 3) downstream impacts, including ground water flow from the sinkhole and surface water impacts from the proposed project. The criteria also recognized that sinkholes are a natural part of the hydrologic setting, and that engineering or structural solutions may not always be the most appropriate.

Based on initial discussions with representatives of the SWCDs and local landowners, common sinkhole treatment objectives included: 1) protecting groundwater quality; 2) preventing erosion or further enlargement of the sinkhole; 3) reducing unsafe conditions; and 4) providing usable land.

Once site-selection criteria and common treatment objectives were identified, a design methodology was developed. The purpose of the design methodology was to provide information to SWCD technicians to assist in their evaluation of applicable sinkhole treatments, selection of potential sinkhole treatments, and development of preliminary design and cost estimates. A standardized design methodology was also useful because of limited funds available for site investigation.

A literature review of sinkhole treatment measures was conducted to identify potential treatments and review performance of the treatments. A multidisciplinary team of professionals experienced in water resource engineering, agricultural engineering, geotechnical engineering, geology, and hydrogeology evaluated the potential treatments and developed a framework for meeting the proposed criteria and objectives. The framework, shown in Table 1, provides generally recommended treatments based on the treatment objective and the many physical conditions of the sinkhole, its watershed, and geology that should be considered during design. Potential sinkhole treatment practices were divided into three groups: 1) best management practices; 2) filling techniques; and 3) other measures. The discussion below provides a general description of the sinkhole treatments and their use in this program.

\section{Best Management Practices (BMPS)}

The primary reason for implementing BMPs as sinkhole treatments is to improve the quality of "run-in" water. In some cases, BMPs will prevent further enlargement of the sinkhole or provide more usable land. Several BMPs that were put into place as part of this program are discussed below.

Watershed BMPs and Conservation Practices - Perhaps the most effective method of improving the quality of water entering the sinkhole is to put BMPs into place within the watershed to reduce the amount of contaminants transported from the site. Where appropriate, structural practices such as vegetated filter strips, grassed waterways, and stream bank protection were designed into the sinkhole treatments.

Surface Water Diversion - The direct contamination of groundwater from surface water at a sinkhole can be reduced by diverting the surface water through an open channel or in a pipe. Many of the sinkholes treated under this program relied on a surface water diversion to improve water quality and prevent expansion of the sinkhole.

Surface Water Controls - In some cases it is not feasible to divert runoff away from a sinkhole. Runoff that cannot be diverted can be controlled to improve the quality of the water entering the sinkhole by allowing sedimentation and the removal of certain contaminants. These measures can also provide a controlled hydraulic drop that will minimize erosion around the sinkholes. 


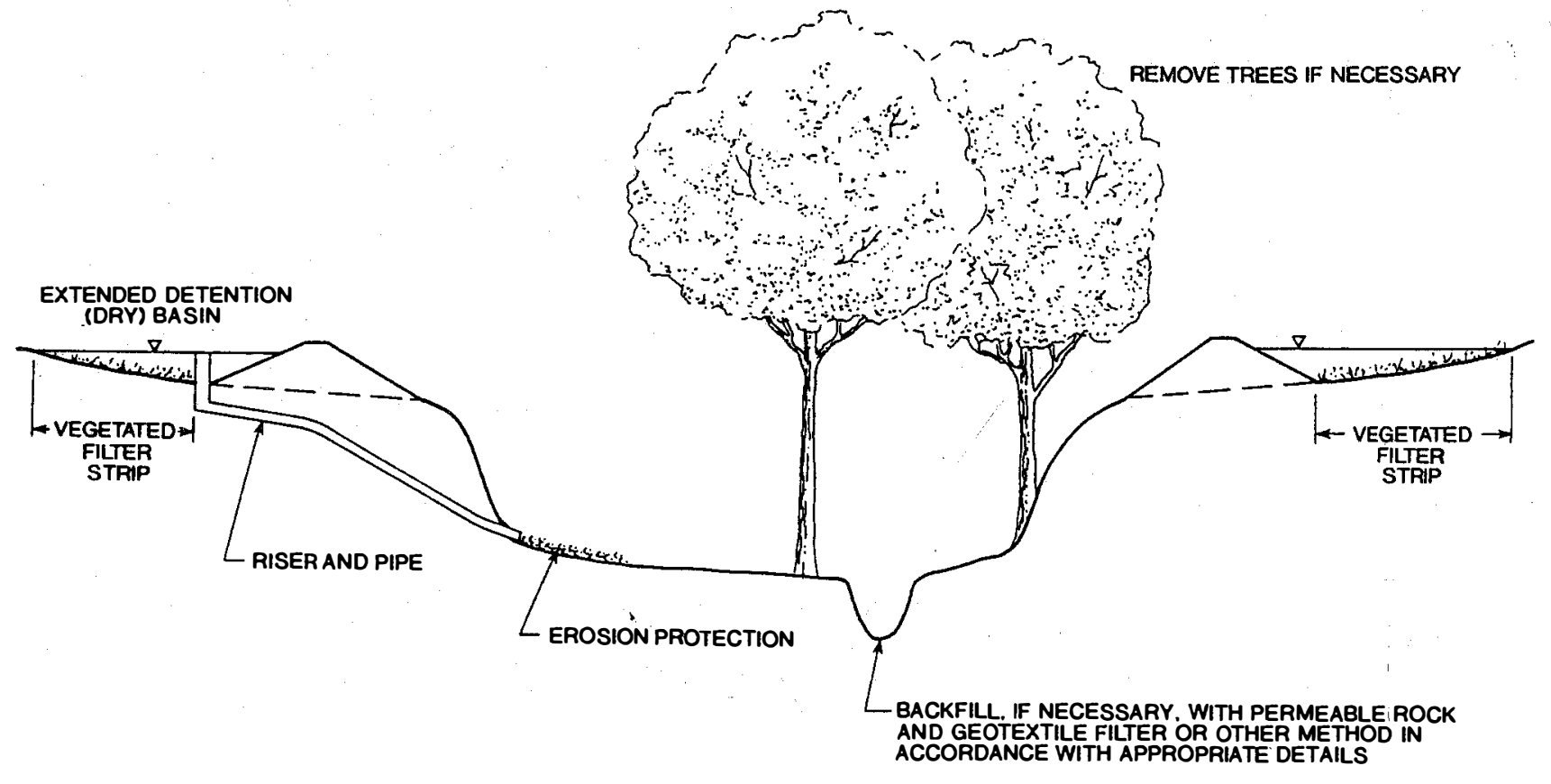

Figure 1: CONCEPTUAL SKETCH OF SURFACE WATER CONTROL

An example of such a surface water control is shown in Figure 1. Other BMPs such as vegetated filter strips can be placed around the surface water control to provide additional water quality improvement. In most cases a dry basin is recommended because the extended detention of surface water near the sinkhole could contribute to further sinkhole development in the area.

Surface water controls, such as shown in Figure 1, may remove up to 75 percent of sediment and contaminants attached to sediment if properly designed and maintained (Barr Engineering, 1993). This includes organic $N$, total $P$, and a few of the commonly used pesticides such as paraquat and Treflan. However, most of the common pesticides currently used tend to be transported from the watershed in solution with surface water. Surface water controls are expected to remove some of these pesticides; however, the removal rates are typically expected to be less than 20 percent.

\section{Filling Treatments}

Four methods of filling the sinkhole were considered for meeting the landowner's objectives. As a general rule, the use of sinkhole filling treatments solely as a means of providing farmable or otherwise usable land over the filled sinkhole was discouraged.

With most of the filling techniques, redevelopment of a sinkhole at or adjacent to the treated sinkhole is possible. A monitoring device such as a settlement plate was designed into several of the sinkhole fillings to provide an early waming of rock or soil loss into the bedrock.

Impermeable Seal - Impermeable sinkhole sealing has been used in several areas of the United States (Minnesota SCS, 1981; Pennsylvania SCS, 1990; Wisconsin SCS, 1985). This treatment practice typically consists of the placement of grout or large rocks in or over the bedrock opening, followed by layers of clay and/or plastic.

This treatment practice minimizes the percolation of water to the bedrock opening but could increase the potential for further development of sinkholes, migration of sediment into the bedrock opening, or additional pore-water pressures on an existing cavity.

Permeable Rock Filter - Sinkholes can be filled by placing rocks and aggregate over the bedrock opening or at the base of the sinkhole to form a permeable rock filter. Large rocks at the bottom of the filter are used to bridge the bedrock opening. Additional layers of aggregate and soil material are then placed over the large rocks, with each layer using increasingly smaller rocks than the underlying layer. Geotextile fabrics can be substituted for certain aggregate or soil layers. Each layer is graded to act as a filter that prevents the migration of material downward. 

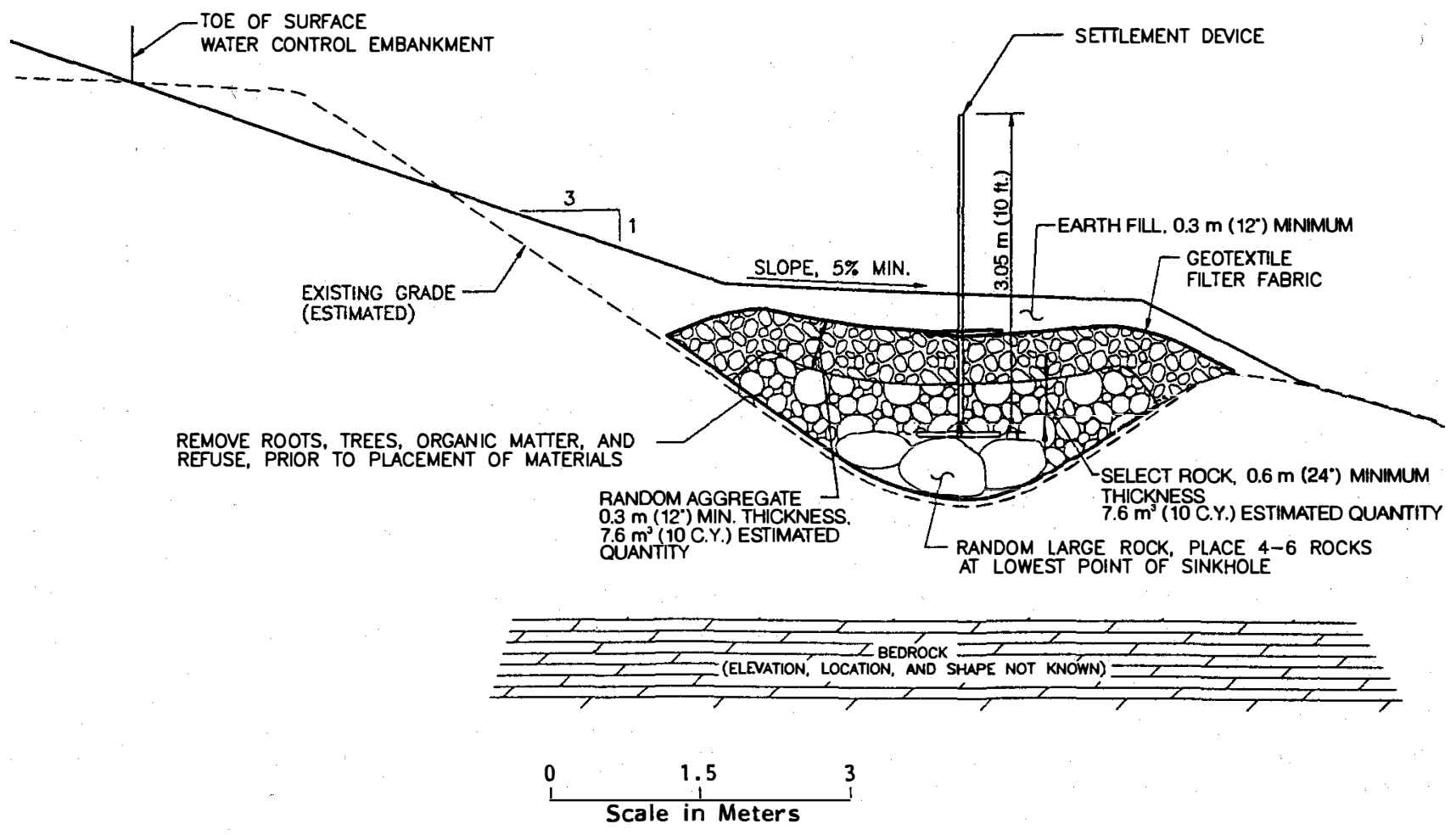

Figure 2: EXAMPLE OF PERMEABLE ROCK FILTER USED AT A SINKHOLE TREATMENT SITE

It is this filtering that prevents the further loss of native soil to the sinkhole and distinguishes this treatment from the filling of the sinkhole with random aggregate and soil materials. Figure 2 is an example of a permeable rock filter design.

A permeable rock filter was designed for three of the sinkholes treated as part of the cost-share program. The permeable rock filter has since been used to treat sinkholes in this area and has been an effective means of filling small sinkholes.

Rock/Pipe Drain - The rock/pipe drain (Adams and Lovell, 1984 and West Virginia SCS, 1991) is a means of sinkhole filling that provides surface drainage to the bedrock opening. The drainage is conveyed to the bedrock opening in rock and/or a pipe. This practice has not been put into place under the program.

Concrete Bridge or Geosynthetic Bridge - A concrete bridge consists of a layer of reinforced concrete placed over the bedrock opening. The concrete bridge is recommended in situations where a large or highly fractured bedrock opening exists or where a sudden redevelopment of the sinkhole poses a significant risk to life or personal property. A reinforced concrete layer can bridge large bedrock cavities and should be placed over stable limestone: This practice is used extensively by the Minnesota Department of Transportation in road construction projects in the area.

The geosynthetic bridge consists of layers of geosynthetic material and aggregate placed within the soil fill over the bedrock opening. This treatment has been used under roadways in Pennsylvania to provide a safety net that resists complete collapse and limits deflections over the void (Boneparte, 1987).

\section{Other Treatments}

Slope Stabilization - Stabilization of slopes is an option at large sinkholes where filling is not desired or is too costly. This treatment consists of flattening the soil slopes, establishing turf on them, and implementing other measures to reinforce or protect them as necessary. Water-control measures may be added to ensure that the stabilized slopes do not erode. 
Compaction - Compaction techniques seek to densify the soil over a cavity or cause a planned collapse of the cavity. Compaction techniques include deep compaction and vibro-compaction.

Grouting - Grouting involves the injection of grout into the underground bedrock cavity. A low-slump grout is typically used in order to bridge small limestone voids and minimize the amount of grout needed. This technique has been used by the Minnesota Department of Transportation to treat several sinkholes in southeastern Minnesota.

Groundwater Control - This treatment practice involves placing a vertical barrier to prevent the migration of water and sediment into bedrock voids. The vertical barrier could consist of a slurry wall or vertical synthetic membrane. This treatment is usually cost prohibitive for most agricultural sinkholes and would likely be used only in special cases.

\section{DUSCHEE CREEK PROJECT}

The Lanesboro state fish hatchery is located near the city of Lanesboro, in Fillmore County, Minnesota (Figure 3). The hatchery is a major supplier for the fish-stocking programs of the Minnesota Department of Natural Resources (DNR). The hatchery is supplied by large springs discharging from the Oneota Dolomite of the Prairie du Chien group at the base of a bluff. For many years, the hatchery springs experienced water quality problems, including high levels of sediment, nitrate, and bacteria, especially after storm events. The sediment and nitrate are of particular concern to the hatchery managers because of their effects on the fish stock.

The west branch of Duschee Creek is intermittent, flowing only in wet conditions. In the past, stream flows would enter a streamsink (sinkhole) located 2 miles south of the hatchery (labeled D101 on Figure 3), near the contact between the Shakopee dolomite and New Richmond Sandstone formations.

Dye-trace studies have confirmed that water sinking at this streamsink, and also at another sinkhole, flows to the hatchery springs with a transit time of around 10 hours. Based on the dye-trace studies, the DNR suspected that this streamsink was a major contributor to the sediment and nitrate problems in the springs during runoff events.

The DNR was particularly concerned that a storm event could coincide with a major fertilizer and pesticide application which could potentially kill millions of dollars' worth of fish stock. In this situation, an engineering solution was clearly applicable.

\section{Treatment Design and Construction}

The objective of the Duschee Creek sinkhole treatment was to minimize contamination of groundwater and the springs at the Lanesboro fish hatchery by diverting the creek from the existing streamsink and filling the sink area.

The channel diversion was designed to convey stream flows away from the sinkhole to provide the hydraulic capacity of the existing channel. Filling of portions of the existing channel were performed in conjunction with excavation of the channel diversion. A drop structure was constructed at the upstream end of the channel diversion to stabilize the horizontal location of the stream and the channel profile and to minimize upstream erosion associated with shortening of the channel length.

A permeable rock filter was designed to fill the sinkhole area to minimize further inflow of surface water to the sinkhole and prevent possible contamination of the springs due to vandalism (deliberate contaminants in the streamsink could have resulted in large fish kills at the hatchery). This permeable filter allows some groundwater flow to continue to the bedrock; however, it virtually eliminates surface water inflow to the sinkhole.

Excavation of the sinkhole area occurred for a period of three days to a depth of approximately $8.5 \mathrm{~m}$ ( 28 feet) below the initial streamsink. The permeable rock filter was placed at the base of the excavation to form a "blanket drain." Large rocks (approximately $0.5 \mathrm{~m}$ to $1.0 \mathrm{~m}$ in diameter) were placed at the base of the excavation to assist in bridging underlying voids that may occur below the extent of the excavation subsequent to the project. Increasingly smaller rocks and aggregate, as well as geotextile filter fabric, were placed in the excavation to form a graded filter that would minimize future loss of overlying fine soil materials into the bedrock cavity. Native lean clay soil was placed over the geotextile filter fabric and compacted.

A settlement plate was placed within the lowest rock layer. This plate will be used to monitor settlement of the rock materials and overlying soils.

Preliminary results indicate the diversion was successful in improving water quality in the hatchery springs. Since its installation, there have been no incidents of increased sediment content in the springs following storm events. 


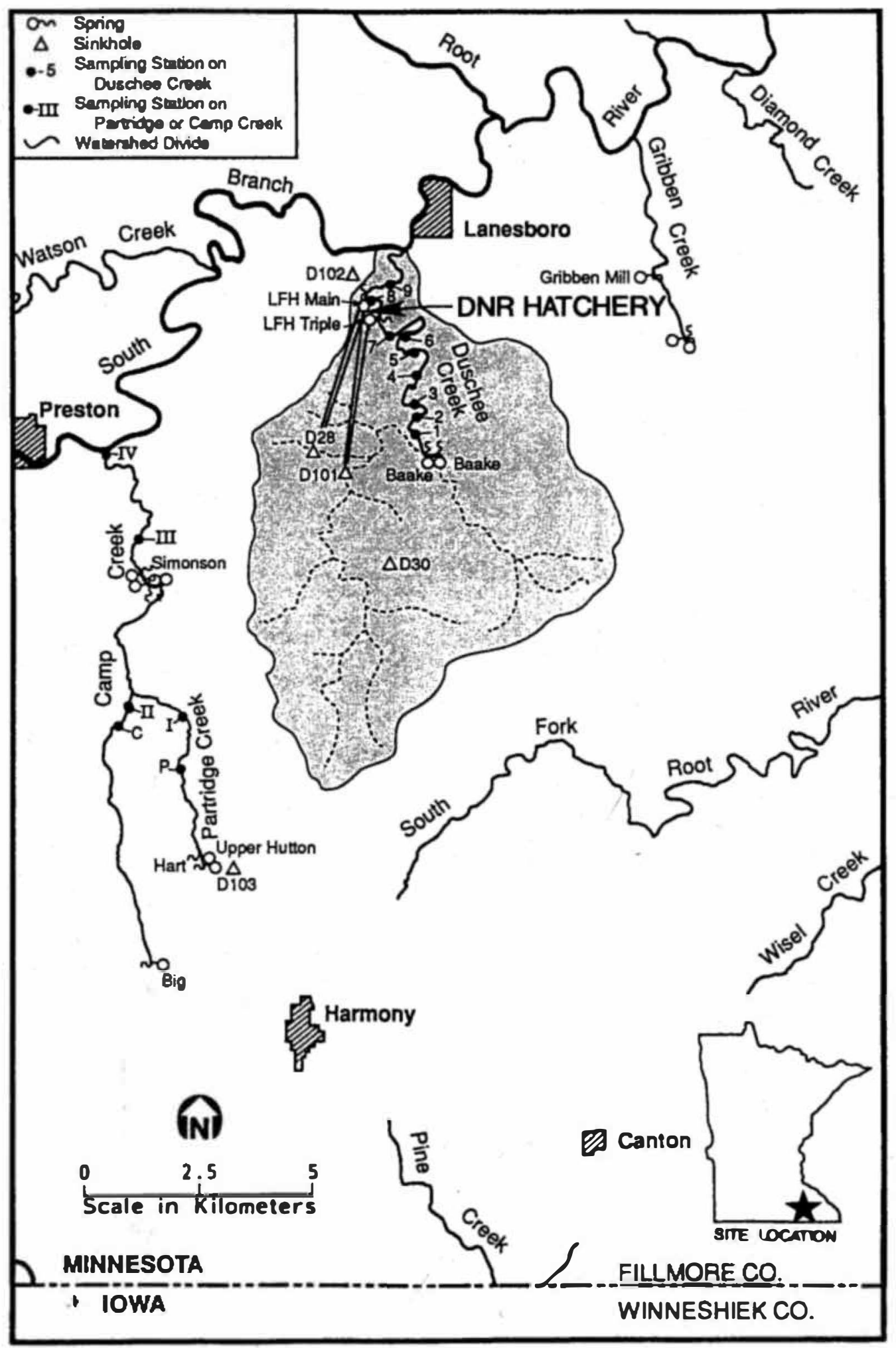

Figure 3: DUSCHEE CREEK STUDY AREA 


\section{CONCLUSION}

The State sinkhole treatment program designed to provide financial and technical assistance to landowners in southeastern Minnesota was effective at developing methods to reduce water quality degradation and erosion.

Potential sinkhole treatments were reviewed by a multidisciplinary team. A design methodology or framework was developed to provide the basis for the program's sinkhole treatments. The design methodology was developed to provide information to SWCD technicians to assist in their evaluation of applicable sinkhole treatments, selection of potential sinkhole treatments, and development of preliminary design and cost estimates. The design methodology provides generally recommended treatments based on the treatment objective and the many physical conditions of the sinkhole, its watershed, and geology that should be considered during design.

Potential sinkhole treatment practices were divided into three groups: 1) best management practices; 2) filling techniques; and 3) other measures. Where appropriate, these treatment methods were designed and constructed.

A stream diversion and sinkhole filing project was constructed as part of the program. This project was successful at reducing water quality problems at a nearby fish hatchery.

\section{REFERENCES}

Adams, F.T., and Lovell, C.W., 1984, "Geotechnical Engineering Problems in the Karst Region of Southern Indiana", July 3, 1984, Purdue University, West Lafayette, IN.

Barr Engineering Co., 1993, "Basis for Sinkhole Treatment Decisions", February 1993.

Bonaparte, R., and Berg, R.R., 1987, "The Use of Geosynthetics to Support Roadways Over Sinkhole Prone Areas", Karst Hydrogeology: Engineering and Environmental Applications, Proceedings of the Second Multidisciplinary Conference on Sinkholes and the Environmental Impacts of Karst, Orlando, Florida, February 9-11, 1987, pp. 437-435.

USDA, Soil Conservation Service, Minnesota, 1981, "Sinkhole Treatment", August 1981.

USDA, Soil Conservation Service, Pennsylvania, 1990, "Sinkhole and Sinkhole Area Treatment", PATG Sec. IV, July 1990.

USDA, Soil Conservation, West Virginia, 1991, "Construction Specification 400 Sinkhole Treatment Field Trial", August 1991.

USDA, Soil Conservation Service, Wisconsin, 1985, "Crevice and Sinkhole Treatment", Section IV, Technical Guide, August 1985. 


\section{KARST GEOHAZARDS}

\section{ENGINEERING AND ENVIRONMENTAL PROBLEMS IN KARST TERRANE}

Edited by

BARRY F.BECK

P.E.LaMoreaux \& Associates, Inc., Oak Ridge, Tennessee

(Formerly: Director of the Florida Sinkhole Research Institute)

Assisted by

FELICITY M.PEARSON

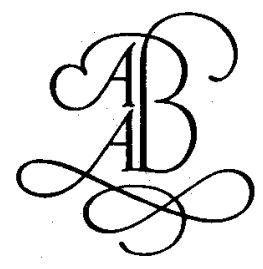

Sponsored by

P.E.LaMoreaux \& Associates, Inc. and Co-Sponsored by

The National Groundwater Association

The American Society of Civil Engineers, Tennessee Section Institute for Geotechnology, University of Tennessee Karst Waters Institute

\section{A.A.BALKEMA/ROTTERDAM/BROOKFIELD/1995}

